\title{
MODELO PARA A IMPLANTAÇÃO OU REVITALIZAÇÃO DE TRABALHOS DE CONCLUSÃO DE CURSO
}

Saupe R, Wendhausen ALP, Machado HB. Modelo para a implantação ou revitalização de trabalhos de conclusão de curso. Rev Latino-am Enfermagem 2004 janeiro-fevereiro; 12(1):109-14.

A exigência estabelecida pelas Diretrizes Curriculares de um Trabalho de Conclusão de Curso para a área de enfermagem é uma inovação para a maioria dos cursos no Brasil. Somente alguns, devido a uma visão prospectiva, implantaram essa modalidade de estudo. Essa exigência tem demandado esforços das universidades no sentido de que esses estudos representem não somente um exercício acadêmico, mas também um indicador de qualidade institucional e possível contribuição para a solução de problemas sociais. O modelo que propomos inclui a definição de linhas de pesquisa, a aglutinação de pesquisadores por área de interesse, a organização de grupos e núcleos de pesquisa, a definição dos tipos de estudos privilegiados, o planejamento de agendas operacionais, o acompanhamento da implementação e o incentivo à divulgação.

DESCRITORES: pesquisa; monografia; normas

\section{MODEL FOR INTRODUCING OR REVITALIZING THE FINAL MONOGRAPH}

The requirement set by the Curricular Guidelines for a Course Conclusion Work in the nursing area is an innovation for the majority of courses in Brazil. Only a few courses have introduced this type of study as a result of their forward-looking vision. This requirement has demanded an effort from the universities, to ensure that these studies do not only represent an academic exercise, but also an institutional quality indicator and a possible contribution to the solution of social problems. Our proposed model includes: defining lines of research, gathering researchers per by area of interest, organizing research groups and centers, defining the preferred types of studies, planning operational agendas, carrying out a follow-up on their introduction and encouraging their publication.

DESCRIPTORS: research; monograph; standards

\section{MODELO PARA LA IMPLANTACIÓN O REVITALIZACIÓN DE TRABAJ OS DE CONCLUSIÓN DE CURSO}

La exigencia establecida por las Directrices Curriculares de un Trabajo de Conclusión de Curso (TCC) para el área de enfermería es una innovación para la mayoría de los cursos en Brasil. Solamente algunos, por cuenta de una visión prospectiva, implantaron esta modalidad de estudio. Esta exigencia ha demandando esfuerzos de las universidades en el sentido que estos estudios representen no solamente un ejercicio académico, sino también un indicador de calidad institucional y posible contribución para la solución de problemas sociales. El modelo que proponemos incluye la definición de líneas de investigación, la aglutinación de investigadores por área de interés, la organización de grupos y núcleos de investigación, la definición de los tipos de estudios privilegiados, la planificación de agendas operacionales, el acompañamiento de la implantación y el incentivo a la divulgación.

DESCRIPTORES: investigación; monografía; normas

\footnotetext{
${ }^{1}$ Enfermeira, Doutor em Enfermagem, Pesquisador CNPq, Professor do Curso de Mestrado Profissionalizante em Saúde, e-mail: saupe@amja.org.br;

2 Enfermeira, Doutor em Enfermagem, Coordenador do Curso de Mestrado Profissionalizante em Saúde, e-mail: aguejor@matrix.com.br; ${ }^{3}$ Enfermeira, Mestre em Enfermagem, Articuladora de Pesquisa - Curso de Enfermagem, e-mail: heloisa.beatriz@terra.com.br. Universidade do Vale do Itajaí
} 
INTRODUÇÃO

O acompanhamento da elaboração e implementação dos Projetos Político Pedagógicos (PPP) dos Cursos de Graduação em Enfermagem (CGE) têm identificado, entre outras, a preocupação com a implementação ou revitalização dos Trabalhos de Conclusão de Curso (TCC) ou Monografias. Essa preocupação é procedente na medida em que, além de exigência das Diretrizes Curriculares, para a maioria dos cursos é uma inovação que não encontra professores experientes, já que em sua formação não foi incluída essa atividade. Somente alguns cursos, devido a uma visão prospectiva, implantaram essa modalidade de estudo. Tal exigência tem demandado esforços das universidades no sentido de que os trabalhos representem não somente um exercício acadêmico, mas também um indicador de qualidade institucional e possível contribuição para a solução de problemas sociais.

Alguns estudos têm contribuído para a compreensão e valorização do TCC. A maioria ${ }^{(1-3)}$ aborda questões relativas à importância da iniciação científica precoce para aguçamento da visão crítica, treinamento de metodologias, refinamento da capacidade de trabalhar com orientação e em grupo e enfrentamento menos doloroso da obrigatoriedade de produzir uma monografia. Mais recentemente, pesquisadores ${ }^{(4)}$ investigaram como os alunos vivenciam o processo de elaboração de suas monografias. A maioria dos sujeitos $(71,9 \%)$ relatou que, ao iniciar o curso de graduação em enfermagem, não acreditava em sua capacidade de desenvolver uma monografia e sequer conhecia o sentido dessa palavra. As principais dificuldades enfrentadas no processo foram relativas às referências bibliográficas, assistência do orientador, falta de treino em leitura, prevalecendo aquelas dificuldades relacionadas à redação. Todavia, a maioria dos sujeitos mencionou sentimentos e/ou emoções positivas ao ver sua monografia concluída.

A experiência das autoras deste artigo com essa temática resultou na construção de um modelo que, tendo sido concebido para o Curso de Enfermagem da UNIVALI, veio a ser compartilhado com outros colegas através de discussões paralelas ocorridas em algumas oportunidades. Nesse compartilhar houve interesse em conhecer o modelo mais detalhadamente, o que nos levou a este artigo.

O modelo proposto inicia com o conhecimento consolidado no curso através da produção de professores e alunos. A análise dessa produção identifica as linhas de pesquisa privilegiadas e fornece subsídios para sua adequação à proposta da CAPES, para a área de enfermagem, procurando adequá-la à vocação do curso. Definidas as linhas de pesquisa, promove-se a aglutinação dos professores, conforme especialidades e temas de interesse e a construção de projetos articulados que vão orientar as propostas de $\mathrm{TCC}^{(5)}$. Como se percebe, esse modelo dá ênfase a estudos permanentes, nos quais o professor é que define a temática, procurando ajustá-la aos interesses dos alunos. Na seqüência emerge o Núcleo de Pesquisa como conseqüência natural dos procedimentos anteriores, sem a artificialidade das propostas verticais. O Núcleo passa então a ser referência para todas as iniciativas de seus componentes.

Esse modelo inclui uma fundamentação, o estabelecimento de alguns princípios, as etapas de desenvolvimento do aluno com as competências a serem enfatizadas, a operacionalização, incluindo a definição de atribuições e clareza quanto à propriedade intelectual dos dados e as modalidades de estudos aceitas. Passamos a seguir a detalhar cada um desses itens.

\section{FUNDAMENTAÇÃO}

Essa opção de valorizar e incrementar o processo de pesquisa na graduação tem como ponto de partida nosso entendimento de que a mesma pode ser tomada como princípio científico e educativo. A pesquisa deve aparecer em todo trajeto educativo que tem como base qualquer proposta emancipatória ${ }^{(6)}$. Assim, é necessário desmistificá-la em relação à separação artificial do ensino, o reconhecimento de sua articulação com a prática e a superação do modelo que vê a aprendizagem como domesticação do aluno.

Tendo como base essas premissas, entendemos que a melhor (nunca a única) metodologia para aprender pesquisa é "fazendo pesquisa". E a melhor maneira de fazer pesquisa é trabalhando em grupos, com projetos vinculados às linhas de pesquisa. Alguns Cursos de Enfermagem já vêm se articulando nesse sentido e tomando as iniciativas necessárias à consolidação de tal perspectiva. Entendemos também que o processo de "fazer pesquisa" precisa ser alimentado pela reflexão e pelo conhecimento metodológico, sistematicamente atualizado, revitalizado e que incorpora as tendências da atualidade, 
sem perder de vista os compromissos e a história da profissão.

O trabalho grupal e a vinculação dos projetos à linhas de pesquisa, além de atender as políticas atuais dos órgãos de fomento, ultrapassa duas tendências cristalizadas no processo de pesquisar, quais sejam, que todo projeto, mesmo de iniciação, deve partir de uma idéia "original" e "inédita" e que o processo de pesquisar é uma atividade solitária. Entendemos que a construção do TCC resulta numa experiência muito mais enriquecedora e de qualidade quando enfrenta os desafios do trabalho grupal. As críticas originárias dos pares preparam os futuros profissionais para a argumentação procedente quando, no futuro, essas críticas partirem de outras áreas. Mas, se trabalhar em grupo, enfrentando os avanços e retrocessos naturais nesse tipo de prática, já é um desafio considerável, convencer alunos e professores de que devem ater-se a uma linha de pesquisa, na qual os estudos vão se sucedendo e aprofundando, ainda é mais complicado, pois o interesse e satisfação ainda estão muito atrelados ao "fazer algo que ninguém fez ainda".

Nesse sentido, e considerando dois aspectos (processo grupal e estudo inédito) somos contrárias a obrigar que todos sigam essa proposta. Esgotadas as possibilidades de convencimento, através da sedução e argumentação, é preciso deixar aos autores o direito de tentar, acertando ou errando.

Sabemos que não vamos fazer de todos os alunos "pesquisadores", mas se conseguirmos que valorizem a pesquisa, saibam ler e criticar os relatórios de investigações, incorporem os resultados convenientes à sua prática, já teremos atingido nossos principais objetivos. $\mathrm{E}$, nesse percurso, teremos possibilitado o crescimento da maioria e evidenciado aqueles que têm perfil mais aproximado para a pesquisa e a pós-graduação.

Todavia, todo esse investimento em pesquisa não necessita negar a possibilidade de construção do conhecimento através de outras modalidades de estudos. Assim, podemos manter o diálogo para que o Trabalho de Conclusão de Curso (TCC) possa resultar, também, de relatos de experiências práticas fundamentadas em testes de teorias ou outras modalidades.

Princípios: iniciação precoce, sucessivas aproximações, complexidade crescente, processo pró-ativo, flexibilização

Entendemos que a iniciação em pesquisa deve acontecer o mais precocemente possível. Com isso acreditamos que a aprendizagem será mais bem incorporada, bem como possibilitará o reconhecimento dos alunos com perfil mais adequado à pesquisa e que serão recomendados para bolsas e outros incentivos que se apresentem. A iniciação precoce encaminha ao princípio seguinte, favorecendo sucessivas aproximações entre o aluno e o processo da pesquisa. Essas sucessivas aproximações precisam ser planejadas pelos professores envolvidos com o TCC, e podem/devem abordar as várias etapas da pesquisa, desde sua concepção até à divulgação dos resultados obtidos. O princípio da complexidade crescente inicia o aluno para tornar-se primeiramente um leitor crítico e um consumidor seletivo dos resultados de pesquisas e vai, gradativamente, envolvendo-o com as etapas da pesquisa, participação em grupos, incentivo ao debate, treinamento para coleta de dados, aplicação de instrumentos e a discussão dos resultados mais significativos. O processo pró-ativo estimula iniciativas dos alunos, abrindo espaço para discussão e encaminhamento de temas de pesquisa, gerados a partir de seus interesses, cuja viabilidade, ou não, será percebida pelo protagonista da idéia, na medida em que avancem na revisão da literatura sobre o tema e nas discussões no grupo. O princípio da flexibilização possibilita incorporar, como créditos optativos ou atividades complementares, a participação nos grupos de pesquisa e a produtividade daí decorrente, desde que aprovadas pelo Colegiado de Curso, bem como incorporar como TCC os projetos desenvolvidos e vinculados a programas de iniciação científica ${ }^{(7)}$.

Etapas de desenvolvimento do aluno: capacitação, conceptualização, produção, divulgação

Entendemos que a primeira etapa para o desenvolvimento do aluno é sua capacitação, entendida como a apreensão de conhecimentos sobre como fazer pesquisa. Essa etapa concentra-se em conteúdos sobre metodologia científica, bioestatística, metodologia da pesquisa, leituras de resultados de pesquisas e entrevistas com pesquisadores. A conceptualização representa a busca pela temática a ser desenvolvida. Como a proposta é trabalhar com projetos integrados, oportuniza-se que os professores, pesquisadores e orientadores do curso venham divulgar suas pesquisas, expondo suas sugestões para os projetos dos alunos que quiserem se filiar à sua 
linha de pesquisa. A produção representa o tempo da construção do projeto, o planejamento, o embasamento teórico, a coleta dos dados, sua análise e elaboração do relatório final. A divulgação inicia com a apresentação e sustentação do TCC perante Banca Examinadora e continua com seu encaminhamento para eventos ou periódicos, sob a forma de artigo, resumo ou pôster.

Nesse sentido, é importante que a Matriz Curricular, entendida como o conjunto de conteúdos e experiências de aprendizagem consideradas importantes para atingir o Perfil Profissional estabelecido no Projeto Pedagógico, inclua encontros entre o tema pesquisa e 0 aluno, nos vários semestres letivos. Consideramos mais efetivo o planejamento organizado em parcelas menores, mas constantes, do que aquele concentrado somente em alguns semestres.

\section{Operacionalização}

Entendendo a pesquisa como processo e sua operacionalização ocorrendo de forma compartilhada, em grupos, vinculados a um núcleo de pesquisa, as autoras descrevem como vêm desenvolvendo essa etapa. $O$ conjunto constituído por articuladores, orientadores e orientandos constitui o Núcleo de Pesquisa, coordenado pelo líder. Articuladores são professores do Curso com capacidade para produzir, avaliar e orientar pesquisas e que articulam professores orientadores e acadêmicos em torno de uma linha de pesquisa e de um grupo de apoio para construção e desenvolvimento de seus projetos. Orientadores são professores do Curso com capacidade para desenvolver e orientar pesquisa, que preferencialmente possuam projetos de pesquisa ao qual se acoplam os TCCs sob sua orientação; orientandos são alunos de graduação ou pós-graduação, filiados a um projeto de TCC ou outro projeto de iniciação científica reconhecido pelo Curso.

O Núcleo está organizado em Grupos de Apoio conforme Linhas de Pesquisa definidas a partir das competências dos articuladores e tradição consolidada no curso quanto à Produção Científica. Os Orientadores, na medida do possível, filiam-se a esses grupos conforme identidade com as linhas de pesquisa definidas pelos articuladores.

Os projetos são definidos a partir das discussões e prioridades estabelecidas no grupo, incentivando-se que cada Orientador tenha o seu Projeto e que os estudos produzidos pelos orientandos representem subprojetos vinculados ao mesmo.

A construção dos Projetos passa por etapas de trabalho individual (estudo particular necessário a cada aluno conforme suas necessidades), grupal (grupo de alunos, com o orientador e/ou com o articulador) e é socializado nos Seminários.

Os Seminários são os momentos em que o articulador, orientadores e seus respectivos orientandos, ao longo de um período (que pode ser um semestre ou mais), avaliam em conjunto os projetos de TCC desenvolvidos ou em desenvolvimento e discutem a possibilidade de inter-relação entre os projetos vinculados ao grupo de apoio. Os projetos podem ser apresentados de acordo com a etapa em que o aluno se encontre para que, aos poucos, ele possa aprimorar tanto a elaboração do mesmo, como treinar sua argumentação perante 0 grupo. Por exemplo: inicialmente constroem o tema/ problema do estudo e seus objetivos e apresentam ao grupo para que opine e assim por diante, em cada nova etapa.

Formalmente o processo de aprovação do projeto envolve o cumprimento de algumas etapas a fim de garantir sua qualificação e posterior encaminhamento para a Comissão de Ética em Pesquisa da Universidade (CEP). Dessa forma, finalizadas todas as etapas do projeto ele é entregue, geralmente ao final de um semestre, e avaliado pela Articuladora responsável pelo grupo de apoio em que estava inserido com a colaboração dos professores orientadores, vinculados ao grupo, e, em seguida, avaliado por mais uma Articuladora. O resultado dessas avaliações e as correções sugeridas ficam registradas em ata e são discutidas com o orientador e seus orientandos e o projeto é reformulado até que fique em condições de ser avaliado pelo Comitê de Ética (que é externo ao Curso). Até sua aprovação final pelo Comitê de Ética, esse documento é tratado como anteprojeto. Após a aprovação pelo CEP, passa a ser designado projeto de pesquisa, e os acadêmicos estão liberados para iniciar a coleta dos dados e dar início à sua monografia.

Questões não resolvidas no âmbito do Grupo de Apoio e/ou Articulação, à luz do Regulamento de TCC do Curso de Enfermagem, serão encaminhadas ao Colegiado do TCC do Curso de Enfermagem, composto pela Coordenadora do Curso, Articuladores de Pesquisa e Professor Orientador.

Questões relativas à propriedade intelectual dos 
dados também devem ser previstas. Assim, entendemos que os dados coletados na implementação do Projeto de TCC aprovado são de propriedade dos alunos autores do mesmo e do orientador. No Relatório e Resumo, publicados pelo Curso ou Universidade, os alunos são os autores e o professor consta como orientador e co-autor. A ordem da autoria (primeiro, segundo, terceiro autor) dos trabalhos publicados a partir desses dados, como artigos, capítulos, etc... será consensada entre os autores, que assinarão "Declaração de Responsabilidade", confirmando a efetiva autoria e/ou "Transferência de Direitos Autorais", quando não quiserem ou não puderem participar da construção de outras modalidades de divulgação do TCC.

Modalidades de estudos

Propomos um modelo inspirado em Conhecimento e Interesse ${ }^{(8-9)}$ e a inclusão da Pesquisa Convergente Assistencial ${ }^{(10-11)}$. Com isso pretendemos diversificar as possibilidades para desenvolvimento do TCC, vinculado ao processo formativo do(a) enfermeiro(a), incorporando as seguintes modalidades de estudos e pesquisas:

- Pesquisa Clássica: com enfoque empírico-analítico, que tem como fundamento epistemológico a idéia de um mundo previamente estruturado; prioriza o método em função de sua lógica; o acesso aos fatos se dá pela observação e quantificação da realidade.Tem como pressupostos subjacentes: a universalidade da teoria - seus princípios não se vinculam a qualquer contexto específico; a neutralidade da teoria - demarcação rigorosa entre afirmações científicas e afirmações quanto a valores e objetivos pessoais; a totalidade é decomposta em variáveis que podem ser mensuradas e controladas - o particular e único é abandonado em favor da generalização. Compreende as pesquisas denominadas quantitativas, experimentais e quase-experimentais e sua tipologia inclui estudos descritivos, prospectivos, retrospectivos.

- Pesquisa Histórico-Hermenêutica: trabalha com símbolos criados e usados pelo homem; produz conhecimentos baseados nos métodos interpretativohistóricos; o acesso aos fatos se dá pela compreensão dos símbolos inventados pelos homens para se comunicarem e interpretarem os acontecimentos da vida; a compreensão ocorre mediante um processo dialógicoconsensual e tem por finalidade orientar a ação; a objetividade se define como o resultado de um consenso intersubjetivo, obtido na interação social; o consenso de uma comunidade científica determina o que é verdadeiro e válido; o conhecimento científico é condicionado cultural e historico. Inclui estudos orientados por metodologias qualitativas.

- Pesquisa Praxiológica: objetiva não só apreender a realidade, mas também transformá-la; a realidade não está previamente estruturada e, por isso, deve ser apreendida na relação dialética do sujeito e do objeto; a realidade não pode ser compreendida independentemente dos determinantes históricos, das condições estruturais e da autobiografia dos indivíduos; a evolução do homem é mais do que um simples desenrolar cronológico, genético ou orgânico, constitui também um processo social e histórico. Adota o conceito de práxis, que significa ação e reflexão: pela reflexão o homem identifica e se liberta de seus condicionamentos e pela ação ele cria e recria suas instituições. Estudos que utilizam método essencialmente dialético.

- Pesquisa Convergente Assistencial ${ }^{(10)}$ : inspirada na pesquisa-ação de Kurt Lewin e no processo de cuidar conforme as teorias de enfermagem, é entendida como "aquela que mantém, durante todo o seu processo, uma estreita relação com a situação social, com a intencionalidade de encontrar soluções para problemas, realizar mudança e introduzir inovações na situação social; portanto, esse tipo de pesquisa está comprometido com a melhoria direta do contexto social pesquisado". O ato de assistir/cuidar está incluído no processo de pesquisar. Apoiando essa perspectiva autores ${ }^{(11-12)}$ colocam que, assim como o assistir, o cuidar e o ensinar, a pesquisa é uma dimensão da prática de enfermagem e deve estar inter-relacionada às demais; a pesquisa em enfermagem tem sua origem na realidade de saúde das pessoas, grupos ou comunidades ou em questões específicas da profissão; a produção da pesquisa, a divulgação e a utilização dos resultados são partes integrantes de um mesmo processo permeado pela ética. Consideramos que a realidade nos oferece um vasto campo para a pesquisa, e a metodologia as ferramentas para o seu desenvolvimento e que, para avançar o processo de construção do conhecimento em enfermagem, a prática deve ser constantemente objeto de pesquisa.

Essas modalidades incluem os vários tipos de estudo que podem ser viabilizados, e que deverão estar detalhadamente explicitados e colocados à disposição dos alunos e orientadores para consulta, tanto na forma impressa em papel quanto virtual. Assim, podemos ter 
pesquisas experimentais, estudos de caso, etnográficos, históricos...que priorizem dados quantitativos ou qualitativos ou a inter-relação deles.

\section{CONSIDERAÇOES FINAIS}

Acompanhar o desenvolvimento e crescimento dos alunos no processo de criação de seus Trabalhos de Conclusão de Curso é uma das melhores gratificações que pode resultar do desempenho das funções de educadores comprometidos. Mas é preciso reconhecer que esse espaço pedagógico transita na luta dos contrários, prazer e sofrimento. Melhor dizer sofrimento e prazer, pois, na jornada que representa, os momentos prazerosos são momentos mesmo e o sofrimento é mais evidente e permanente.

Sem a pretensão de considerar que a proposta deste modelo vai suprimir o sofrimento, acreditamos que poderá minimizá-lo na medida em que representa uma organização de suporte ao aluno e ao orientador. Todavia é preciso ter muita clareza de que é um processo de permanente recomeço, e é nessa rotina do recomeço a cada semestre que podemos desgastar nossa criatividade

\section{REFERÊNCIAS BIBLIOGRÁFICAS}

1. Lopes CM. Produção de conhecimento por enfermeiros assistenciais: sua utilização na prática. [Tese]. Ribeirão Preto (SP): Escola de Enfermagem de Ribeirão Preto/USP; 1990. 2. Padilha MICS, Carvalho MTC. O aluno de graduação e a pesquisa científica. Rev Esc Enfermagem USP, 1998; 27(2):281-395.

3. Siliprandi E, Heinig LS, Severino R. Pesquisa em enfermagem: conhecimento dos alunos sobre pesquisa e sua opinião quanto ao ensino e desenvolvimento da monografia. [Monografia]. Itajaí (SC): Curso de Graduação em Enfermagem/UNIVALI; 2000.

4. Fernandes AS, Pelá NTR. A vivência dos formandos em enfermagem e obstetrícia na elaboração de sua monografia. Centro Universitário Barão de Mauá [online] 2001 julh/dez [citada em 8 jun 2002]; 1(2) [7 telas]. Disponível em: URL: http://www.baraodemaua.br/revista/v1n2/artigo06.html

5. Saupe R, Machado HB, Wendhausen AL. A pesquisa como princípio educativo: concepção para o curso de enfermagem. Projeto Pedagógico: da identidade dos cursos aos referenciais ético - políticos da UNIVALI. In: $7^{0}$ Fórum Institucional de Integração Universitária; 2001. 24 e 25 de julho, Itajaí: UNIVALI; 2001. p.34-7.

6. Demo P. Pesquisa: princípio científico e educativo. São Paulo (SP): Cortez; 1991. e empenho. Precisamos ter presente que mesmo que para os professores seja uma rotina semestral, que começa quase sempre do zero, para os alunos tudo é novo e desafiador. Olhar para trás e rever o início daqueles que já estão em etapas mais avançadas é uma forma de encontrar estímulo para o recomeço, pois um erro freqüente é começarmos a exigir sempre mais das novas turmas, esquecendo do inédito que representa toda essa experiência.

Outro cuidado importante diz respeito à valorização dos acertos em todas as etapas, ou seja, de considerar o TCC como um processo educativo e científico. Pois se a pesquisa já é freqüentemente considerada como uma exigência a mais no curso, na qual é referida dificuldade de articulação com o cotidiano e a realidade da profissão, da qual muitos alunos abdicariam caso não fosse obrigatória, sem o estímulo necessário a toda ação humana, teremos alunos sentindo-se como "vivendo uma prova de fogo" ${ }^{\text {(13) }}$, a qual precisam vencer para tornaremse Enfermeiros. Assim estará comprometido todo nosso empenho em transformar nossos futuros colegas em profissionais que reconhecem e valorizam a contribuição da pesquisa para a qualidade do cuidado e o crescimento da profissão.

7. Pereira LO, Inocenti A, Silva, GB. A iniciação científica na graduação em enfermagem de Universidade de São Paulo (1993 a 1996): análise crítica. Rev Latino-am Enfermagem 1999 julho; 7(3):77-86.

8. Habermas J. Conhecimento e interesse. São Paulo (SP): Abril; 1980.

9. Boufleuer JP. Interesses humanos e currículo: paradigmas, tendências ou dimensões? Educ e Real 1993 julh/dez; 18(2):97-108.

10. Trentini M, Paim L. Pesquisa em enfermagem: uma modalidade convergente assistencial. Florianópolis (SC): UFSC; 1999.

11. Daher DV, Santo FHE, Escudeiro Cl. Cuidar e pesquisar: práticas complementares ou excludentes? Rev Latino-am Enfermagem 2002 março-abril; 10(2):145-50.

12. Elsen I, Nitscke R. Pós-graduação, pesquisa e ética: um tema acima de qualquer questionamento? Texto Contexto Enf 1994 jan/junho; 3(1):7-19.

13. Ângelo M. Vivendo uma prova de fogo: as experiências iniciais da aluna de enfermagem. [Tese]. São Paulo (SP): Instituto de Psicologia/USP; 1989. 